\title{
Impact of Professional Stress and Career Development on Organizational Commitment Among Nurses
}

\author{
Mehvish Kiran*1 ${ }^{* 1}$ Muhammad Hussain ${ }^{2} \quad$ Mohammad Afzal $^{3}$ Syed Amir Gillani ${ }^{4}$ \\ 1.Lahore School of Nursing, The University of Lahore, Pakistan \\ 2.Faculty of Allied Health Sciences, The University of Lahore, Pakistan
}

\begin{abstract}
Introduction: Organizational commitment is a challenge for the nursing profession. Each organization has own environment for professional, and this impact on employ's organizational commitment. In order to increase job commitment, efficiency, productivity, and effectiveness of employees, each organization must reduce the level of stress and increase career development among employees through providing of the good working atmosphere (Ruzungunde, Murugan, \& Hlatywayo, 2016). Methodology: A descriptive correlational study was carried out in Jinnah hospital Lahore among staff nurses. Total 172 female staff nurses were (Staff nurses and senior staff nurses) participated in the research age group of 21-45 years. Results: Statistical Analysis showed that professional stress $(\mathrm{M}=4.0373, \mathrm{SD}=.41216)$, career development $(\mathrm{M}=4.1536, \mathrm{SD}=.84719)$ and organizational commitment $(\mathrm{M}=$ $2.2483, \mathrm{SD}=.51568$ ) had moderate level. Professional stress had a statistically significant negative impact on organizational commitment $(\mathrm{r}=-.058, \mathrm{p}<0.01)$ and career growth had a significant positive impact on organizational commitment $\left(\mathrm{r}=.488^{* *}, \mathrm{p}<0.01,0.05\right)$. Conclusion: This study was designed with particular predictions that every organization needs to realize the importance of organizational commitment among employees. So, it is very essential for every organization to provide that environment which reduces the level of professional stress and increase career development. Stress-free working environment in a hospital have tremendous effect for both the organization and its staff nurses.
\end{abstract}

Keywords: Professional stress, career development, and organizational commitment, nurse.

DOI: $10.7176 / \mathrm{JHMN} / 62-09$

Publication date:May $31^{\text {st }} 2019$

\section{Introduction}

Health organization have a very complex environment in which different professional accomplish their responsibility. Nursing profession is one of them which have own important professional responsibilities. Each organization have own environment for professionals, and this impact on employ's organizational commitment. Organizational commitment is known as the willingness of workers to work hard on behalf of an organization to get the goals of an organization. There are many factors which affect organizational commitment, the most common factor is occupational stress and career growth. Many scholars described that organizational commitment is influenced by occupational stress and it reduce the level of employer's commitment to their organization (Sow, 2015). Organizational commitment is also affected by career growth. In an organization, the employees who have more opportunities to build up their career growth, the level of organizational commitment is higher among them (Haque, 2014). Organizational commitment enhances the abilities of their employees because if they are engaged and satisfied with their job then they do their best for the development of an organization. They pay their duties with more attention. They complete their all task with responsibility because they thought their value and value of an organization is the same. They feel proud to accomplish the responsibilities of an organization. These characteristics demonstrate the commitment of employees to their organization. In an organization, the commitment of employees drives their all efforts for a better outcome. The commitment of nurses to their organization shows that they are satisfied with their work. The effective engagement of employees to their organization plays a vital role and it provides better opportunities to enhance their characteristics at a workplace (Dempsey \& Reilly, 2016). Organizational commitment of employees to their organization is very important. It plays a major role to satisfy their subordinates. If they have a high level of commitment then they can stay at an organization for a long time. They can accept all rules and policies of their organization and think about the success of their organization. They may feel relaxed to be a part of an organization. Organizational commitment is the field of organizational behavior. Employees 'loyalty can be defined as workers are being committed to the achievement of their organization and believing that working for this organization is their best option (Iqbal, Tufail, \& Lodhi, 2015). Occupational stress is a major problem at workplace. There are many sources which can increase occupational stress. At workplace, heavy workload, manage the work of other people and have poor abilities to fulfill them may cause occupational stress. Hospital staffs usually work beyond the capacity of activity. They face many problems and cannot cope with working policies. The Occupational stress is a destructive physical and emotional reaction which happened when the requirements of work do not organize the abilities(Ruzungunde et al., 2016).Job stress is a result or response to a certain stimuli in the atmosphere. Nowadays, work related stress has become more apparent and leads to low self-esteem of staffs. The causes of job stress can be hospitals rules 
and regulations, clashes between the employees and organizational views, ineffective communication and low guidance from superiors and senior subordinates (Divakar, 2015). Stress is a negative feeling and effects the physical health of people. There are many problems associated with the health of employees due to occupational stress. The common problem which finds in health care employees may be headaches, indigestion, tiredness, too much eating or drinking, difficulty in sleep and tendency to sweet. These long lasting disorders can promote physically and mentally problems among employees. Which can influence their job performance, job satisfaction and organizational commitment (Antonova, 2016). Career growth is a process which requires many characteristics of employees to observe their career goals and plans for their better development and implementation. Organizational career growth is known as a program which is provided by an organization. The organization may do effective planning to develop the career of their employees. It can enhance the knowledge and skills of their employees through a proper training program and by providing proper feedback. Career counselor and manager may provide support and guide to take a batter decision to increase career growth and may improve working performance. Employees would be able to build up their abilities and skills if the organization arrange a proper training program for them (Yang, Liu, Liu, \& Zhang, 2015). As the organizational environment is becoming so advanced and it challenges the employees for better career growth. So, it is noticed that the growth of the career is the responsibility of employees not their organization. But supervisors and senior subordinate can help to develop individual career growth and professional commitment. If employees push their efforts to develop their career, they may achieve their goals. Self-motivation can encourage employees to search out new training programs for better role performance which may enhance personal skills and knowledge. However, hardworking might be increase career growth and professional skills in employees, which may also help to gain reward and fulfill personal goals (Luck, Wilkes, \& O'Baugh, 2015; Rehman, 2017).

\section{Problem Statement}

Now a day's organization facing many challenges related to human resources, one of them is employee organizational commitment. It is sound that committed human power moves the organization in the right direction for achieving the organization goal, but non-commitment can lead to poor outcomes of an organization. If employees are not committed to their organization, they cannot achieve their task in their duties. They may be disloyal to their organization and may show aggressive behavior. They may take a wrong decision to leave the job. Non-commitment may cause absenteeism. There are many contributing factors in non-commitment of employ such as: occupational stress and career growth. When professional stress is increased then commitment can reduced and it would have negative impact on organizational commitment. If career development increases, the motivation, the self-esteem, and the personal satisfaction also increases and employ are more committed. Professional stress and career development have a major role in organizational commitment. There is no study done in our context of university of Lahore that career growth and job stress influence organizational commitment. So, this research work will explore the impact of professional stress and career development on organizational commitment among nurses. The presence of work stress has been proven by previous studies to decrease employee's commitment towards the organization (Hashim \& dan Perakaunan, 2016). Organizational commitment is influenced by career development if employees have a high level of career development, then they have a more effective commitment to their organization (Bai \& Liu, 2018).

\section{Objectives of the Study:}

- To determine the impact of professional stress and career development on organizational commitment among nurses.

- To identify the level of professional stress, career development and organizational commitment among nurses.

\section{Theoretical Framework:}

According to Mayer and Allen's framework which was first developed in 1991, known as Mayer and Allen three component organizational commitment model that was first time implemented on organizational commitment. The requirements of the study are fulfilled by this framework. According to Mayer and Allen's those variables which identify with the work and setting, impact the administrative commitment. They establish that there is an extraordinary connection between work-related stress and organizational commitment. Organizational commitment is influenced by job related stress and career development. 


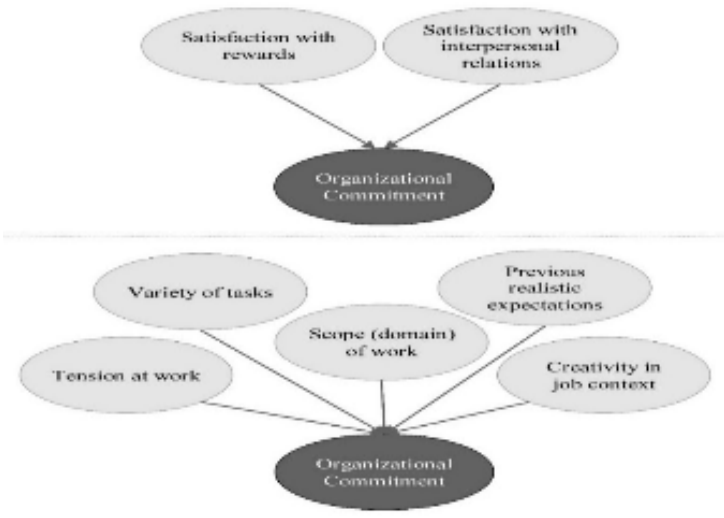

(Leite, Rodrigues, \& Albuquerque, 2014)

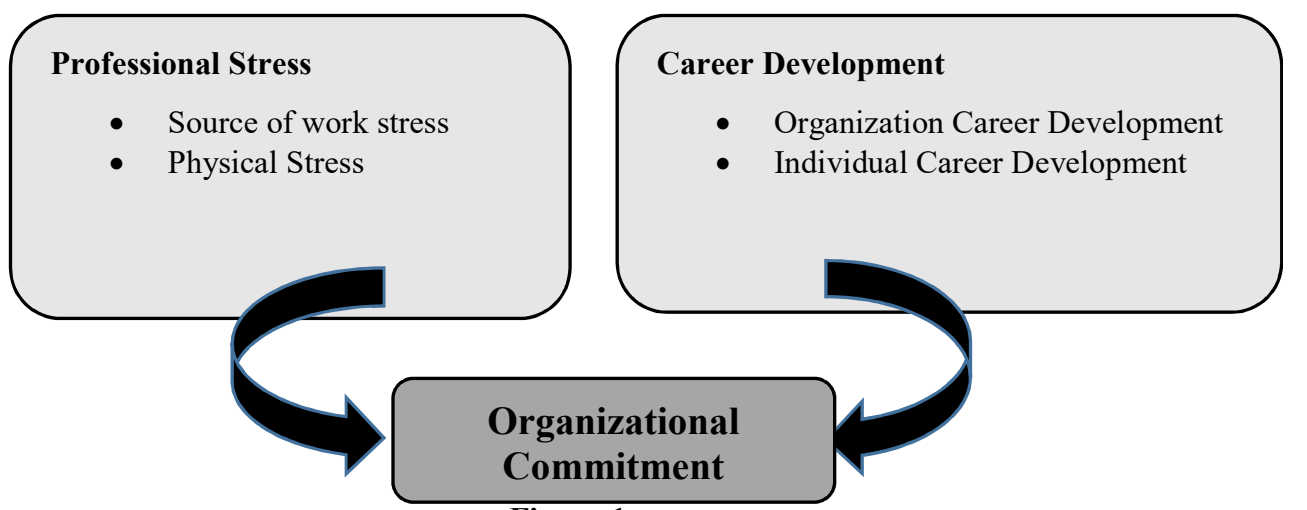

Figure.1

Figure 1 show the conceptual model of this study. It described that factors which affect the organizational commitment. It reveals that work-related stress and career development may affect the organizational commitment. Occupational stress is an independent variable and it have further sub domains which are source of work stress and physical health. Career growth also independent variable and it have two sub domains which are organizational career growth and individual career growth. These all factors that affect administrative commitment. Thus the hypothesized theoretical framework shows that:

- Occupation stress may have some impact on organizational commitment among nurses.

- Career growth may have some impact on organizational commitment among nurses.

Significance of the Study:

This study will be significant for the organization, study participants, and professional because the findings of this study give right information about the impact of occupational stress and career growth on organizational commitment among nurses. On behalf of this information policy maker / decision maker and concerning authority can take sufficient measure and use motivation strategies (through seminar, workshop and counselling etc.) for reducing occupational stress and advancing the career growth which can increase the organizational commitment of nurses. By doing this employee can improve their job performance which can ultimately increase organizational performance. Committed employs will provide the quality care which improve the repute and prestige of hospital and in turn reduce costs for the healthcare organizations as well as individuals. The findings of this study will provide information to investigator or researcher about the impact of occupational stress and career growth on organizational commitment among nurses, which can serve as a guide for further research in this area. The study finding will help the Staff nurses of this organization to cope with occupational stress by using strategies like discussion with teachers, mentors and staff which help to develop their career growth and enhance their commitment. This action may improve quality of care and enhance the staff nurses learning, ultimately it will develop the staff nurses 'interest at clinical practices.

\section{Literature Review}

The main aim of this study is to define the influence of job stress and career development on administrative commitment among nurses. It is clear that work-related stress and career growth significantly affect organizational commitment. On the other hand, this evidence is not fully reinforced that relationship among these variables. To 
offer more piece of evidence and logic for this relationship, review of literature is very helpful. There are many views and concept for commitment for example integrity, work ethic, propensity, and responsibility. It is also known as an attitude and direction to an organization. Organizational commitment is very helpful to recognize the identification of employees towards an organization (Arbabisarjou, Sarani, Mohammadi, \& Robabi). Employees' satisfaction in a well-structured organization is very necessary because it plays a vital role in the establishment of management. There are three unique sorts of commitment, which are affective, normative and continuance. Effective commitment is the worker's connection to their association and remain happy with their work. They have an emotional attachment and accept all assignment related to their work because they thought their place of work is a fantastic place. In Normative commitment, employees realize their responsibilities with an organization. Continuance commitment is related to work and promotion of employees. In a successful organization, job satisfaction and organizational commitment is closely related to each other (Intan et al., 2014). A correlational study was conducted at a therapeutic school clinic, in Bangladesh in 2014 to evaluate the level of administrative commitment. The mean of administrative commitment was 2.59 and this showed the high level of administrative commitment among nurses (Haque, 2014). In 2015, a descriptive correlational study was conducted among managers of different hospital in Australia. The aim of the study was to measure the relationship between provisions of adequate guidance and employee organizational commitment. The result of the study showed that adequate guidance positively influenced the commitment of workers to their administration. Employee organizational commitment's mean score was 6.12 and it lies toward the advanced end of the scale, showing that there is a relatively high level of EOC in the hospital (Baird, Tung, \& Yu, 2017). A study was carried out to identify the association between job-related stress and administrative commitment in Mazandaran Tax Organization of Iran. In the real word, according to employees the relationship between job-related stress and organizational commitment is negative. But the result of this study revealed that there was a significant positive relationship among job-related stress and administrative commitment. Such as the occupational stress of employees was increased, their commitment was also increased (Mojtabazadeh, Samadi Miarkolaei, \& Samadi Miarkolaei, 2016). Organizational commitment is influenced by job related stress. In health care departments it is a very necessary to decrease the level of work-related stress between employees. There are many studies which demonstrate that reducing the level of occupational stress may lead to organizational commitment. It is very helpful element for a better succeeding competence of organization (Alipour \& Kamaee Monfared, 2015). A study was conducted among nurses of Jimma Zone public hospital, the findings of the study revealed that the mean of the source of work stress is $58.08 \pm 12.62$. The ratio of stress due to workload is $56.7 \%$ among nurses. Although this study show that there was a level of occupational stress was high among nurses (Dagget, Molla, \& Belachew, 2016). A descriptive correlational study was conducted at Aspet A. Company Limited to assess the impact of work related stress on work performance among employees. The results of this study showed that the most common sources of stress was heavy workload and its mean was 3.48, work the level of activity and its mean score was3.33. However clashes between employees and organization showed fourth source of work stress its mean was 3.30 (Enyonam Peace Amoako, , \& David, 2017). A study was conducted among Iranian's nurses to assess the level of occupational stress and its sources. The findings of the study show that there was moderate level of occupational among nurses. Generally, 26\% respondents of study showed that their occupation was very stressful. The most common source of occupational stress was low salaries and its mean was 3.79 and due to heavy work load and its mean was 3.67 and poor guidance and its mean score was3.48 (Mohammad Mosadeghrad, 2014). A study findings show that career growth affects the organizational commitment, there was a positive relationship among these variables. When organizations develop the employee career through the implementation of best training and development programs, then employees are more satisfied and relaxed towards their work and in a result, their commitment is also increased towards the organization. Training and career counseling is important for employers and employees. If organizations conduct the proper training sessions for employees, it would help them develop their skills and competencies and in the outcome they increase their commitment (Rehman, 2017). Professional development is personal to individual nurse professional, she needs high level of clinical expertise, education, leadership opportunities, commitment and competency, develops herself through personalized training, researches, evidenced base practice among others. To develop clinical expertise, self-study, skills and knowledge(Modupe O. Oyetunde, 2015). In Iran Universities of Medical Sciences, a study was conducted to assess the importance of personal skills for career development. The results of this study showed that career growth required individual, interpersonal, and useful skills (Sheikhi, Fallahi-Khoshnab, Mohammadi, \& Oskouie, 2016). A cross sectional study was conducted among nurses in teaching hospital of China. Organization play an important role in the development of career growth because adequate guideline and support help employees increasing their career growth. The findings of this revealed that nurses had moderate level of organizational career growth and its mean score was $2.40 \pm 0.50$. The mean score of organizational support and manager guidelines were $4.11 \pm 1.12$ (Sheikhi et al., 2016). 
III.Methodology

Study Design: A descriptive correlational study was used to determine the impact of professional stress and career development on organizational commitment among nurses.

Study Site: The site of the study was nurse's counters of indoor departments Jinnah hospital Lahore.

Study Setting: The study was conducted at Jinnah hospital, Lahore.

Target Population: The entire registered nurses of indoor counters were participated in this research. The total size of indoor registered nurses was 300 .

Sample Size: The sample size of this study was 172 Nurses that is calculated by using formula. Formula include was $n=\mathrm{N} / 1+\mathrm{N}(0.05) 2$ (Ellen, 2018; Slovin, 1960)

Sampling Technique: Convenient sampling techniques was used in this study.

Duration of the Study: This study was taken approximately 4 months (January 2019, to April 2019).

Inclusion criteria: The subjects who was included in the study were: All staff nurses and senior staff nurses, all female nursing staff, age 21-45 year, those nurses who are willing to participate in the study, all indoor department (Medical, surgical, pediatrics, Orthopedic, Obstetric, Nephrology and private wards) nurses.

Exclusion criteria: The subjects who was excluded from the study were: All other nursing staff who are not registered, those who are not willing to participate, all male, all nurses from outdoor departments and critical intensive care units.

Instrument

Three quantitative instrumental questionnaires on measuring of occupational stress, career growth, and organizational commitment was used on Likert scale which is adopted by the cited of Akramul Haque "relationship between occupational stress and career growth with organizational commitment among nurses" (2014).

\section{Data Collection Plan}

After taking informed consent, data was collected by the researcher the helped of pre-tested data collection tool (questionnaire/ performed). Data was collected according to the variables of the questionnaire which were as follows. Demographics data was taken from the participants. The question was asked according to variables of the study.

Data Analysis:

Data was analyzed by using SPSS version 21.0 statistical software for data analysis. This study was descriptive and all the descriptive study was obtained through SPSS.

Ethical Consideration: The rules and regulations set by the ethical committee of Lahore School of Nursing was followed while conducting the research and the rights of the research participants was respected.

- Written informed consent attached was take from all the participants.

- $\quad$ All information and data collection was kept confidential.

- $\quad$ Participants was remained anonymous throughout the study.

- $\quad$ The subjects was informed that there were no disadvantages or risk on the procedure of the study.

- $\quad$ They was also informed that they was free to withdraw at any time during the process of the study.

- $\quad$ Data was kept in under key and lock while keeping keys in hand. In laptop it was kept under password.

\section{IV.Results}

This chapter has three sections such as Section I and Section II. Section I deals with demographic characteristics of participants and section II deals with the hypothesis and objectives of the study. 
Section- 1

Table 1.1 Demographic Characteristic of Participants

\section{Descriptive Analysis of Demographic Characteristics of Participants}

\begin{tabular}{llcc}
\hline Statement & Valid & Frequency & Percent $=\%$ \\
\hline Gender & Female & 172 & 100.0 \\
Age Group & $21-25$ yrs. & 95 & 55.2 \\
& $26-30$ yrs & 49 & 28.0 \\
Qualification & $31-35$ yrs. & 18 & 10.5 \\
& 36-40yrs & 10 & 5.8 \\
& Diploma in nursing & 150 & 87.2 \\
& BS Nursing & - & - \\
& (Generic) & 22 & 12.8 \\
Marital status & BS Nursing (Post & & \\
& RN) & & 29.7 \\
Current Position & Married & 51 & 70.3 \\
& Unmarried & 121 & 100.0 \\
Work Experience & Staff nurse & 140 & 81.4 \\
& Senior staff nurse & 32 & 18.6 \\
& $1-5$ years & 72 & 41.9 \\
& 6-10years & 53 & 30.8 \\
& $11-15 y e a r s$ & 22 & 12.8 \\
& $16-20$ years & 25 & 14.5 \\
\hline
\end{tabular}

The above table shows that $100 \%$ of the participants are female. Highest percentage of participants $55.2 \%$ belongs to the age group of $21-25,28.0 \%$ belongs to the age group $26-30$ years, $10.5 \%$ belongs to the age group $31-35$ and $5.8 \%$ belongs to age group 36-45 years. According to qualification $87.2 \%$ of the participants are diploma nursing, $12.8 \%$ are BS Nursing (Post-RN). Regarding the marital status of the participants $29.7 \%$ of the participants are married and $12.8 \%$ are unmarried. As regard to the designation of participants $81.4 \%$ are staff nurses and $18.6 \%$ are senior staff nurses. Work experience of the participants $41.9 \%$ has $1-5$ years of work experience, $30.8 \%$ has $6-10$ years of work experience has $11-15$ years of work experience and $14.5 \%$ has $16-20$ years of work experience.

Section-II

Level of organizational commitment, professional stress and career development

\begin{tabular}{llcl}
\hline Variables & Mean & SD & Level \\
\hline Organizational commitment & 2.2483 & .51568 & Moderate \\
Professional stress & 4.0373 & .41216 & Moderate \\
Source of Professional Stress & .37495 & .37945 & Moderate \\
Physical health & 3.8988 & .64500 & Moderate \\
Career development & 4.1536 & .84719 & Moderate \\
Organizational career development & 3.1846 & .57908 & Moderate \\
Individual career development & 4.2504 & .85500 & Moderate \\
\hline
\end{tabular}

The above table shows the mean of organizational commitment is 2.2483 , according to score transformation it indicates moderate level of organizational commitment among nurses. The mean of professional stress is 4.0373 , it represent moderate level of professional stress. Here the value of career development is 4.2504 , it shows moderate level of career development.

\section{Impact of Professional Stress on Organizational Commitment}

In this section the hypothesis formulated to find out impact of professional stress on organizational commitment among nurses.

Table 3.2 Results of Pearson's Correlation test for Professional Stress and Organizational Commitment

\begin{tabular}{|c|c|c|c|c|c|}
\hline \multicolumn{6}{|c|}{ Correlations } \\
\hline \multirow{4}{*}{$\begin{array}{l}\text { Organizational } \\
\text { Commitment }\end{array}$} & & $\begin{array}{c}\text { Organizational } \\
\text { Commitment }\end{array}$ & $\begin{array}{l}\text { Professional } \\
\text { Stress }\end{array}$ & $\begin{array}{c}\text { Source of } \\
\text { professional Stress }\end{array}$ & $\begin{array}{l}\text { Physical } \\
\text { Health }\end{array}$ \\
\hline & $\begin{array}{l}\text { Pearson } \\
\text { Correlation }\end{array}$ & 1 & -.058 & -.008 & -.120 \\
\hline & Sig. (2-tailed) & & .000 & .000 & .000 \\
\hline & $\mathrm{N}$ & 172 & 172 & 172 & 172 \\
\hline
\end{tabular}

In the above table the results of Pearson's Correlation test shows the value of Pearson's correlation for 
professional stress is -.058 , for source of professional stress is -.008 and for physical health is -.120 and p value for two tailed test of significance is 0.01 . This is significance at the level of $1 \%$. It shows that professional stress, source of professional stress and physical health have impact on organizational commitment and there is negative relation among these variables.

Table 3.3 Results of Pearson's Correlation test for Career Development and Organizational Commitment Correlations

\begin{tabular}{|c|c|c|c|c|c|}
\hline \multirow[b]{3}{*}{$\begin{array}{l}\text { Organizational } \\
\text { Commitment }\end{array}$} & & $\begin{array}{c}\text { Organizational } \\
\text { Commitment }\end{array}$ & $\begin{array}{c}\text { Career } \\
\text { Development }\end{array}$ & $\begin{array}{c}\text { Organizational } \\
\text { Career } \\
\text { Development }\end{array}$ & $\begin{array}{c}\text { Individual Career } \\
\text { Development }\end{array}$ \\
\hline & $\begin{array}{l}\text { Pearson } \\
\text { Correlation }\end{array}$ & 1 & $.488^{* *}$ & .046 & $.490^{* *}$ \\
\hline & $\begin{array}{l}\text { Sig. } \\
\text { tailed) }\end{array}$ & & .000 & .000 & .000 \\
\hline & $\mathrm{N}$ & 172 & 172 & 172 & 172 \\
\hline
\end{tabular}

The above table shows the results of Pearson's Correlation test. The value of Pearson's correlation for career development is $.488^{* *}$, for organizational career development is .046 and for individual career development is $.490^{* *}$ and the $\mathrm{p}$ value for two tailed test of significance is 0.000 . This is significant at the level of $1 \%$. It shows that professional stress, source of professional stress and physical health have impact on organizational commitment. It suggests that there is positive correlation between career development and organizational commitment.

\section{DISCUSSION}

This study is examined the level of professional stress, career development and organizational commitment and finding the impact of professional stress and career development on organizational commitment among nurses. The current study conducted at Jinnah hospital Lahore among 172 staff nurses. Convenient sampling was used to select the sample. The nurses of Jinnah hospital was all female and age between 21-45 years. Most of the staff nurses contributed in this study have a diploma in nursing. The majority of the staff nurses who participated in this study was unmarried $70.3 \%$. The total work experience ranging from 1-20 years. The findings of this showed that staff nurses of Jinnah hospital working in different department had a moderate level of organizational commitment. Azizollah et al. also found that nurses had a moderate level of organizational commitment. Similarly, another study found a moderate level of organizational commitment among nurses (Botswana, 2015). Moreover, another research showed reverse findings that nurses had a high level of organizational commitment (Haque, 2014). The results of the current study showed that nurses had a moderate level of professional stress. Professional stress decreases the commitment of employees to their organization. Another study findings also showed a moderate level of occupational stress among nurses (Vijayan, 2017). The findings of the study also supported by (Haque, 2014). The findings of this research indicated that nurses had a moderate level of career development. The main two components of career development, organizational career development represented that nurses had a moderate level and individual career development also showed that nurses had a moderate level. These findings also supported by (Haque, 2014).According to Pearson's correlation, professional stress have some relationship with organizational commitment and professional stress has a statistically significant negative impact on organizational commitment (Pearson correlation coefficient for professional stress $-.058, \mathrm{P}$ value $<0.000$ ). Similarly, another study found that a statistically significant negative relationship between occupational stress and organizational commitment $\mathrm{r}$ is -.236 , which was significant and $\mathrm{p}$ value is less than 0.05 (Alipour \& Kamaee Monfared, 2015). The findings of this study were also consistent with the findings of (Zhuwao, Setati, P. Rachidi, \& Ukpere, 2015). The findings of this revealed that career development has some impact on organizational commitment. There was a significant positive association between organizational commitment and career development. Pearson correlation coefficient value is .488 and p-value is less than 0.05 . Likewise, another study found the same results that career development had a positive relation with organizational commitment Pearson correlation coefficient value was 327 and p-value is less than 0.01(Haque, 2014). The findings of the current study support the hypothesis. A similar study findings also showed that organizational commitment had a positive relationship with career development. It also indicated that organizational commitment is increased when employees have a high level of career development (Rehman, 2017). Moreover, another study findings also supported the findings of the present study. Jing Bai and Jinping Liu were supposed that organizational commitment had a positive relationship with organizational commitment (Jing Bai, 2018).

\section{Conclusion}

This study identifies the impact of professional stress and career development on organizational commitment among nurses. It is concluded that professional stress has a negative impact on organizational commitment and 
ultimately it reduces the organization commitment of employees. So, each organization needs to reduce the level of stress. Career development has a positive relationship and it enhances the commitment of employees to their organization. Employee's commitment is a function of how actual management is capable to plan and implement good career development program in the organization.

\section{Strength and Limitations}

There are some strength of the present study. Firstly, this study give awareness to organization and participants about the impact of professional stress and career development on organizational commitment. Secondly, there is no any study was found in the context of University of Lahore. Thirdly, this study will serve as a basis in future studies. There are some limitations of this study. As the data was collected from only one setting, it has limited generalizability. A convenient sample was applied in the data collection process whereas the probability sampling method can enhance the induction of different strata of the participants. Another limitation was to collect data by convenient sampling that could give biasness on results. The study was limited to assess the impact of professional stress and career growth on organizational commitment among nurses.

\section{Recommendations}

For future study, it is suggested that data should be collected from more hospital rather than one hospital. Because a hospital is a place where everybody suffers from professional stress. So, it suggested that to minimize the level of professional stress and advancing career growth can enhance the level of organizational commitment among nurses. The findings of the study significant for managers because if they try to control the sources of work-related stress then employees are more committed and provide quality care which increases the repute and prestige of an organization.

\section{Acknowledgment}

With the name of Allah, the most Beneficent and Merciful, the source of knowledge and wisdom to mankind, who has the blessed us with the requisite potential and ability to complete this task in limited time period successfully. All respect to our last Prophet Hazrat Muhammad (S.A.W) who knew the ways of learning knowledge and wisdom for all humanity. Thanks to my dear parents who enable us to get higher education at this level. Researchers are also obliged to the principal Mohammad Afzal School of Nursing, who provide as the great opportunity to conduct research in department. It is my immense pleasure to express my gratitude to my research preceptor $\mathrm{Mr}$. Muhammad Hussain \, faculty member school of Nursing, New campus, The University of the Lahore for providing me valuable suggestion, persistent inspiration and continuous supervisions to complete this research. I am very grateful to all the respondents of Jinnah Hospital Lahore, Who agreed to be filled survey Research Questionnaire allowing us to get valuable information.

\section{References}

Alipour, F., \& Kamaee Monfared, M. (2015). Examining the relationship between job stress and organizational commitment among nurses of hospitals. Journal of Patient Safety \& Quality Improvement, 3(4), 277-280.

Antonova, E. (2016). Occupational Stress, Job Satisfaction, and Employee Loyalty in Hospitality Industry: A Comparative Case Study of Two Hotels in Russia: Master Thesis: Modul University.

Arbabisarjou, A., Sarani, H., Mohammadi, S. D., \& Robabi, H. Organizational Commitment in Nurses.

Bai, J., \& Liu, J. (2018). A Study on the Influence of Career Growth on Work Engagement among New Generation Employees. Open Journal of Business and Management, 6(02), 300.

Baird, K. M., Tung, A., \& Yu, Y. (2017). Employee organizational commitment and hospital performance. Health care management review.

Botswana, D. o. E. G. i. P., a case of Kwazulu-Natal Transaction, in Mobile Money Commitment, Organizational Coercion is Epa an ObscureOTSWANA, DRIVERS OF ECONOMIC GROWTH IN. (2015). Journal of Goverence and Regulation OF GOVERNANCE AND REGULATION.

Dagget, T., Molla, A., \& Belachew, T. (2016). Job related stress among nurses working in Jimma Zone public hospitals, South West Ethiopia: a cross sectional study. BMC nursing, 15(1), 39.

Dempsey, C., \& Reilly, B. (2016). Nurse engagement: What are the contributing factors for success. OJIN: The Online Journal of Issues in Nursing, 21(1).

Divakar, J. (2015). Factors leading to work stress and its impact on employee performance. A case study of Reliance Fresh, India. Dublin Business School.

Ellen, S. (2018). Slovin's Formula Sampling Techniques. Retrieved 4 April, 2019, from https://sciencing.com/slovins-formula-sampling-techniques-5475547.html

Haque, A. (2014). Relationship between Occupational Stress and Career Growth with Organizational Commitment among Nurses of a Medical College Hospital, Bangladesh.

Hashim, N. H., \& dan Perakaunan, F. P. P. (2016). The Impact of Leader-member Exchange on Organizational 
Citizenship Behaviour Readiness Among Local Government Employees in Southern Region of Malaysia. Paper presented at the AND TOURISM RESEARCH CONFERENCE 20-22 APRIL 2016.

Intan, R., Munir, R., Ali, S., Ali, M., Rahman, A., \& Abdul Rahman, R. (2014). Relationship between Job Satisfaction and Organizational Commitment at Health Tourism Hospital in Malaysia.

Iqbal, A., Tufail, M. S., \& Lodhi, R. (2015). Employee loyalty and organizational commitment in Pakistani organizations. Global Journal of Human Resource Management, 3(1), 1-11.

Jing Bai, J. L. (2018). A Study on the Influence of Career Growth on Work Engagement among New Generation Employees. OJBM, 6 No.2. doi: 10.4236/ojbm.2018.62022

Leite, N. R. P., Rodrigues, A. C. d. A., \& Albuquerque, L. G. d. (2014). Organizational commitment and job satisfaction: what are the potential relationships? BAR-Brazilian Administration Review, 11(4), 476-495.

Luck, L., Wilkes, L., \& O'Baugh, J. (2015). Treading the clinical pathway: a qualitative study of advanced practice nurses in a local health district in Australia. BMC nursing, 14, 52-52. doi: 10.1186/s12912-015-0105-7

Modupe O. Oyetunde, K. I. O. (2015). Professional Development and Career Pathway in

Nursing. international journal of Sciences, 4.

Mohammad Mosadeghrad, A. (2014). Occupational stress and its consequences: Implications for health policy and management. Leadership in Health Services, 27(3), 224-239.

Mojtabazadeh, H., Samadi Miarkolaei, H., \& Samadi Miarkolaei, H. (2016). The Relationship between Job Stress and Organizational Commitment in Tax Organization. Journal of Industrial Strategic Management, 1(2), 114.

Rehman, S. (2017). Impact of Career Development on Organizational Commitment. International Journal of Business and Administrative Studies, 3. doi: https://dx.doi.org/10.20469/ijbas.3.10003-3

Ruzungunde, V. S., Murugan, C., \& Hlatywayo, C. K. (2016). The influence of job stress on the components of organisational commitment of health care personnel in the Eastern Cape province South Africa. The International Business \& Economics Research Journal (Online), 15(5), 219.

Slovin, E. (1960). Slovin's formula for sampling technique. Retrieved on February, 13, 2013.

Sow, M. T. (2015). Relationship between organizational commitment and turnover intentions among healthcare internal auditors.

Vijayan, M. (2017). Impact of Job Stress on Employees Job Performance in Aavin, Coimbatore. Journal of Organisation and Human Behaviour, 6(3), 21.

Yang, Y., Liu, Y.-H., Liu, J.-Y., \& Zhang, H.-F. (2015). The impact of work support and organizational career growth on nurse turnover intention in China. International Journal of Nursing Sciences, 2(2), 134-139.

Zhuwao, S., Setati, T. S., P. Rachidi, M., \& Ukpere, W. (2015). Occupational stress and organisational commitment of employees at higher educational institution (Vol. 4). 